\title{
Uma família madeirense de João França: uma saga familiar para refletir (sobre) a mudança dos tempos na Madeira do séc. XX
}

\author{
Uma família madeirense by João França: a family saga reflecting \\ (on) the changing times in 20th century Madeira
}

\author{
THIERRY PROENÇA DOS SANTOS \\ Universidade da Madeira
} 27-

\begin{abstract}
Resumo: Romance póstumo de João França (1908-1996), publicado em 2005 pela Câmara Municipal de Santa Cruz, Uma família madeirense inscreve-se na saga familiar, um género romanesco que visa refletir sobre o percurso das personagens no contexto familiar e social. Além de consubstanciar uma crónica familiar, a força da narrativa de João França reside, em particular, na valorização da componente histórica e também sociológica da Madeira do séc. XX, no período compreendido entre o verão de 1936 (com a revolta do leite em pano de fundo) e o "Verão Quente" de 1975, equacionando os conceitos subjetivos de tradição, rutura e emancipação.
\end{abstract}

Palavras-chave: João França; Madeira; Saga familiar; A revolta do leite (1936); O "Verão Quente" (1975); O declínio da família tradicional

\begin{abstract}
The posthumous novel by João França (1908-1996), published in 2005 by the city of Santa Cruz, A Madeiran Family is a family saga, included in the romance genre, which aims to reflect on the journey of the characters in the family and social context. In addition to fleshing out a family chronicle, the strength of João França's narrative lies, in particular, in the appreciation of the historical and also the sociological component of $20^{\text {th }}$ century Madeira, in the period ranging between the summer of 1936 (with the milk revolt in the background) and the "hot summer" of 1975, equating the subjective concepts of tradition, rupture and emancipation.
\end{abstract}

Keywords: João França; Madeira; Family saga; The milk revolt (1936); The "hot summer" (1975; The decline of the traditional family

Nascido em 1908 no Funchal e falecido em 1996 em Lisboa, João França mudou-se para o continente, em 1938, para abraçar a carreira de jornalista ${ }^{1}$ e, a par dessa profissão, continuou a desenvolver trabalho literário, da prosa ao teatro, passando pela poesia. Com João dos Reis Gomes, Carlos de Freitas Martins e Horácio Bento de Gouveia, João França pertence ao restrito grupo de autores da Madeira que escreveram, pelo menos, três romances de inspiração insular no séc. XX. A sua última obra, Uma família madeirense, cuja preparação estava iniciada em

\footnotetext{
1 Em 1944, entra no diário matutino $O$ Século, "tendo ali atingido o topo da carreira como jornalista internacional" (CALDEIRA, 1989, p. 10). Há de trabalhar com o chefe de redação Acúrcio Pereira, por lá se cruza com Aquilino Ribeiro, a quem pedirá um prefácio para o seu livro de contos Ribeira Brava, publicado em 1953, e trava amizade com o colega Baptista-Bastos.
}

setembro de $1981^{2}$, veio a lume em 2005 , numa edição póstuma, graças à diligência do seu sobrinho, o Sr. Ivo Sinfrónio Martins, e à chancela da Câmara Municipal de Santa Cruz.

\footnotetext{
2 V. a peça jornalística "Entre um e outro banco - Diálogo entre dois escritores madeirenses" da autoria de João França, publicada no Diário de Notícias, da Madeira, de 18 de setembro de 1981, p.3. À pergunta “- Que está a escrever, ou pensa escrever agora?” que Horácio Bento de Gouveia the faz, responde João França: “- Foi por idealizar outro romance puramente madeirense que estou aqui. Vim ver umas coisas e relembrar outras. Até já tenho o respetivo cenário e local de ação: o Caniço. Julgo que o Caniço ainda estará virgem de uma narrativa desse género. Claro, irão surgir dificuldades, não de trabalho da minha parte, isso não, mas sim de empreendimento editorial. Como o doutor bem sabe esse labor no Continente está passando por um momento bastante difícil. Contudo, veremos, até porque não quero parar". Meses depois, saem em prépublicação as primeiras linhas de "Uma Família Madeirense: romance de João França" (de "À semelhança de tantos outros" (...) até "já tinham sido outros dos Oliveiras madeirenses?") na secção "Artes e Letras" da revista Margem, n. 2, Câmara Municipal do Funchal, abril 1982.
} 
Passados mais de dez anos sobre uma primeira tiragem de 500 exemplares, entendeu-se ser oportuno produzir um estudo sobre essa narrativa de ficção para valorizá-la por forma a receber a atenção que merece e justificar a necessidade de uma segunda edição da obra, o que permitiria corrigir as pequenas incongruências ${ }^{3}$ da primeira publicação.

Como o próprio título sugere, Uma família madeirense inscreve-se na saga familiar, um género romanesco com longa tradição no Ocidente que visa, como refere Ludwig Scheidl, "integrar o percurso das personagens no contexto familiar e social" (SCHEIDL, 2011, p. 369). Em regra, essas narrativas de ficção caracterizam-se, de acordo com Yannick Preumont, pelo seu modo de escrita realista, pela importância que confere aos ritos familiares e a tudo aquilo que faz com que o clã central apareça colocado sob o signo da ameaça e do declínio ${ }^{4}$ (PREUMONT, 2004, p.2). Capazes de abranger várias gerações, as mais ambiciosas obras dessa veia literária foram-nos legadas pelo Realismo e pelo Naturalismo, como são disso exemplo o ciclo Les Rougon-Macquart, escrito entre 1871 e 1893 por Émile Zola, o romance verista I Malavoglia, de Giovanni Verga, saído do prelo em 1881, bem como os Buddenbrooks, de Thomas Mann, publicado em 1901. A crónica familiar não tem cessado de renovar-se e, já nessa altura, conhecia uma variante no acompanhamento de uma figura individualizada, como sejam, no caso português, Os Maias (1888), de Eça de Queirós - uma narrativa da decadência de Portugal.

No dizer de Jean-Yves Tadié, o modelo familiar tem a vantagem de oferecer ao romancista uma ordem exterior já pronta a usar, casas que se pode preencher ou deixar vagas 5 (TADIÉ, 1990, p. 94). Além disso, o enredo familiar assenta, ainda de acordo com o ensaísta francês, no jogo contrastivo entre os vários perfis encenados: o drama constrói-se a partir de oposições, entre as gerações ou entre os membros de cada geração ${ }^{6}$ (ibid., p. 94). Por

\footnotetext{
3 Além de alguns erros ortográficos e gramaticais que não comprometem a leitura, o texto oscila entre duas formas - "Mãe de Deus" e "Madre de Deus" - para o mesmo topónimo e apresenta uma incongruência, quando deixa o leitor confuso relativamente à terra de origem da mulher de Jorge: primeiro, adianta-se que era "uma prendada jovem do Estreito de Câmara de Lobos" (FRANCCA, 2005, p. 26) e, depois, é referida como sendo uma "rica e santa senhora do Campanário" (ibid., 2005, p. 94).

4 Adaptação do seguinte enunciado tirado do artigo "La fin des bourgeois de Camille Lemmonier face aux grandes chroniques familiales européennes": "Comme tout roman familial, il se caractérise par le récit de l'évolution d'une famille sur plusieurs générations, par un mode d'écriture réaliste, accorde une grande importance aux rites familiaux et à ce qui fait du clan une communauté que des rapports conflictuels hautement symboliques menacent, et la famille est condamnée au déclin." (PREUMONT, 2004, p. 1-2).

5 Adaptação do seguinte enunciado tirado da obra original Le roman au XXe siècle: "La famille offre au romancier un ordre extérieur déjà prêt, des cases qu'il n'y a plus qu'à remplir ou à laisser vides" (TADIÉ, 1990, p. 94).

6 Adaptação do seguinte enunciado tirado da obra original Le roman au XX siècle: "le signe familial est contrastif: le drame se noue par oppositions, entre les générations ou à l'intérieur de celles-ci”' (TADIÉ, 1990, p. 94).
}

isso, não admira que João França - tal como o próprio explica no breve "introito" que achou conveniente fazer para o romance não ser mal interpretado - tenha procurado insuflar nas suas personagens "liberdade de pensar e de agir", "embora, por vezes, com elas possa estar em desacordo" (FRANÇA, 2005, p. 5). Isto equivale a dizer que a ótica cultural do autor cede lugar ao drama íntimo de cada uma das suas criaturas de papel. Com efeito, é através de um notável jogo de pontos de vista que faz com que as figuras surjam, alternadamente, aos olhos do antagonista - e, por extensão, aos olhos do leitor - como um estereótipo, assegurando, deste modo, o distanciamento irónico do discurso narrativo, sem nunca lhes retirar o verossímil fundo humano que as torna comoventes. Para fazer coincidir a tonalidade do texto com o ambiente descrito e o fluxo de consciência das personagens, João França usa uma linguagem marcada por lugares comuns da psicologia do quotidiano e das situações retratadas, assim como coloquialismos e alguns regionalismos, sempre devidamente contextualizados.

Acresce que este romance pouco extenso de João França (formando um volume de 128 páginas) favorece a componente histórica e também sociológica da Madeira do séc. XX. À semelhança dos romances Cortes (1978), de Almeida Faria, ou O esplendor de Portugal (1997), de António Lobo-Antunes, Uma família madeirense desenrola-se num momento-chave da história do país a que as personagens pertencem (tempos incertos decorrentes da mudança de regime político) e reflete a crise de uma família e dos seus valores, revelando, assim, a resistência e evolução das mentalidades, bem como as tensões sociais latentes.

As mudanças que a Revolução dos Cravos impulsionou e o caso dramático da Revolta do Leite de 1936 constituem temas ainda pouco explorados pelos escritores madeirenses. No tocante àquele "movimento da gente dos lacticínios", parece ser caso único. No contexto nacional e internacional, 1936 representa a viragem para um período negro, como sublinha o romance $O$ ano $d a$ morte de Ricardo Reis (1984), de José Saramago, com o ascenso de Salazar, Mussolini, Hitler e Franco. Quanto ao tema das repercussões socioculturais do 25 de Abril, refira-se a narrativa de ficção Margareta (1980), de Horácio Bento de Gouveia, ou o romance Angélica e a sua espécie (1993), de Irene Lucília Andrade. Na verdade, tais obras perfazem um balanço sobre a própria identidade da Madeira - desde então sem o constrangimento da Censura -, revelando-a nas suas especificidades e perspetivando-a na sua relação com Lisboa ou outras centralidades. Realizado ora "à quente", como é o caso de Bento de Gouveia, ora com uma razoável distância crítica, como sucede com Irene Lucília Andrade, João França opta por deixar ao critério do leitor a interpretação do quadro 
madeirense que delineia, baseado no reconhecimento de identidades individuais e sociais e no conhecimento de dados históricos e políticos.

1. Em Uma família madeirense, João França propõe-se desenhar, em traços largos, o percurso do clã Oliveira ao longo de três gerações. Numa narrativa circular, o livro abre com a visão risonha do espaço-tempo em que a ação se vai realizar - Caniço, "maio de 1975" -, para logo depois apresentar os Oliveiras, uma família fictícia que se perfila como representativa de um tempo, lugar e extrato social demarcados (primeira parte, apenas com dois capítulos). Segue-se uma analepse para o "desgraçado verão de 1936", momento em que factos marcantes da História da Madeira se articulam com episódios relevantes da vida das personagens principais, Bonifácio e a filha, Lúcia (segunda parte, com uma extensão de nove capítulos). Retomando o ponto em que ficara no final da primeira parte, a narrativa salta para o "verão de 1975", encena modos de estar e pensar da terceira geração dos Oliveiras, comenta, através de uma conversa de café, o 25 de Abril, e encerra com o corpo do patriarca em câmaraardente (terceira parte, dividida em quatro capítulos).

O autor vai construir uma genealogia dramática do pai, um patriarca que aflige os que o rodeiam com ideais ultrapassados, dos dois filhos, Lúcia e Jorge, e dos três netos, Benjamim, Venceslau e Marta. Ao lado da família do amo, está a genealogia da família dos serviçais: a caseira Rosa Sabina, que tomou o lugar da mãe, Maria Sabina, e que deverá cedê-lo ao filho, Zé Sabino.

Bonifácio é casado com D. Vicência, exemplo da mulher tradicional e perfeita aos olhos do marido, e, como tal, figura fugaz na economia da intriga. Este casal tem, como já referido, uma filha e um filho. Lúcia casa, a contragosto, com Anselmo, que prefere dedicarse aos negócios, menosprezando a vida de casado. Com profundo desgosto do Comendador que via nisso um castigo de Deus, o casal não assegura descendência. $\mathrm{O}$ Dr. Jorge desposará Cândida, "uma prendada jovem" (ibid., p.26) de família fidalga e rica, e tornar-se-á o braço direito do pai nos negócios da família (vinhos, bordados, frutas). Desempenha um papel secundário no romance, mas tem o mérito de ter dado netos ao patriarca, nomeadamente Benjamim, Venceslau e Marta, sendo esta geração já moldada pela literacia da informação. Benjamim casa com Clara, uma prima da mãe, mas o par não se decide a dar continuidade ao ramo dos Oliveiras. Por seu lado, Venceslau prefere manter-se solteiro. A crónica familiar completa-se com o destaque conferido à figura de Marta, que, como observa Irene Lucília Andrade, no preâmbulo que assinou e que abre o romance de João França: "transporta o cunho duma vontade libertária caracterizando uma viragem histórica e o aparecimento duma e mais esclarecida nova geração" "7 (ANDRADE, 2005, p. 8), ainda que - acrescento eu apresente por momentos acentuado individualismo e tiques de arrogância, acusando a sua condição de menina de família.

O cerne da narrativa tem os seguintes momentos nucleares: o modo risível de como se fez o Livro das origens e feitos da família Oliveira do Caniço; o corte de relações de amizade entre Bonifácio, o monárquico, e Alfredo Meireles, o republicano; a história de amor entre Lúcia e Ricardo Meireles; o casamento arranjado de Lúcia com Anselmo Gomes; o tráfico de influências para viabilizar o projeto da fábrica de manteiga; o acidente de Lúcia, ocorrido quando tinha vinte e um anos e que lhe deixou marcas no rosto para o resto da vida; o verão da Revolta do Leite, na Madeira, em 1936, momento em que o camponês José Talaia será vítima da perseguição política, provavelmente no seguimento da denúncia que o Comendador deve ter formalizado; as lutas e indefinições políticas que o 25 de Abril despoletou; o regresso do filho do Talaia para um ajuste de contas com o passado e a morte do patriarca.

$\mathrm{O}$ romance gira em torno da figura central, o Comendador Bonifácio Jerónimo Vaz de Oliveira, um pretenso fidalgo imbuído de normas anacrónicas, à imagem do seu pomposo nome, que se revê na doutrina de Salazar: "Deus, Pátria, Autoridade, Família, Trabalho" (ROCHA, 2001, p.30). Bonifácio tem esta particularidade: ama o passado, odeia o presente e receia o futuro. Enfatuado, rancoroso e ridículo, quase sempre acompanhado de um periódico regional e da sua caixa de rapé, ora citando a Bíblia, ora enaltecendo o Livro da família dos Oliveiras, seria um protagonista simpático aos olhos do leitor, se não tivesse condenado a filha à infelicidade e "tramado" o camponês José Talaia, depois de este ter tido a ousadia de rejeitar a proposta que lhe fez, acabando provavelmente deportado (para Cabo Verde?). Como descreve Irene Lucília Andrade, no já referido preâmbulo, esse velho é:

retrato nítido do fascismo, feito comendador por mérito industrial, que enfrenta com mau cariz as mudanças políticas e sociais acontecidas ao longo dos anos, comportamento que o torna, por fim, presa da vingança e ajuste dos que por ele foram violados e humilhados (ANDRADE, 2005, p. 7-8).

Se o pai é o fio condutor do ciclo de vida familiar, será naturalmente concedido aos outros membros da família algum espaço para se darem a conhecer, designadamente a linhagem feminina por ser mais problemática, já que a linhagem masculina não foge, no

\footnotetext{
De acordo com a errata fornecida por Irene Lucília Andrade, a autora do preâmbulo, corrigiu-se "literária" por "libertária" e "viagem" por "viragem".
} 
essencial, ao então vigente padrão comportamental. Além do patriarca, caberá, pois, à Lúcia, a filha, e à Marta, a neta, ocuparem o centro da intriga, dando azo a uma visão aguda da identidade feminina, das relações de género e da abordagem do desejo e dos sentimentos.

Lúcia, "igual à mãe, tanto em bondade de alma quanto elegância do corpo" (FRANÇA, 2005, p. 26), enamora-se por Ricardo Meireles, o filho de Alfredo com quem o pai cortou relações. Bonifácio entende unir a filha a Anselmo, o filho do Eng. . Januário Gomes, pelos sagrados laços do matrimónio. Num ato de rebeldia, Lúcia enfrenta o pai dizendo-lhe que a sua afeição vai para Ricardo Meireles, mas acaba por aceitar casar-se com Anselmo, quando vem a saber que Ricardo já tem Mary, a filha do Cônsul inglês. Vai acomodar-se num casamento sem amor e viver numa gaiola dourada cujas grades são os caprichos e preconceitos do Comendador. Ainda assim, quando soube que o pai ia receber em casa Ricardo para tratar de negócios, Lúcia, em nome da jura que fizeram dois anos antes, vai esperá-lo na gruta cimeira, de difícil acesso, que era o segredo deles ${ }^{8}$. Sentindo-se descoberta por uns pastorinhos que a tomam por uma aparição, Lúcia desce apressada, escorrega e embate contra uma tabaibeira ('figueira da Índia'), causando-lhe profundas cicatrizes. Por certo a história do relacionamento de Lúcia com Ricardo confunde-se com o processo da ilusão e da desilusão amorosa, visando fazer sobressair, com lúcido rigor, o engano sobre o qual assenta o sentimento amoroso e o sofrimento que lhe está associado.

Contrariamente à tia, Marta emerge, na última parte do romance, como uma personagem "liberta de complexos". Cursou na Universidade de Coimbra, ouve música pop, usa jeans em vez de saia e não vai à missa. Não se submete aos costumes e valores que o avô preconiza. É ela quem, na cena final do romance, toma a decisão de se livrar, num gesto simbólico, do Livro dos feitos da família Oliveira:

E, sem hesitar, pega no livro da família, embrulha-o numa toalha de linho e desce a escada, a caminho da câmara-ardente.

Pelo tamanho, esse volume agrada à Lúcia. Apressa-se a levantar a cabeça do pai, enquanto a moça também se apressa a colocar-lhe debaixo o retângulo alvinitente. Embora lhe pareça bem agora a posição do morto, Lúcia não está a ver naquele embrulho uma almofada autêntica. A curiosidade leva-a à pergunta:

- Que vem a ser isto, Marta?

Já a afastar-se, a sobrinha responde:

- Nada de importante (ibid., p. 128).

\footnotetext{
8 "Sempre que voltares, e hás de voltar sempre, e eu souber que voltaste, vem até aqui e olha para a minha capelinha secreta. Lá estarei. Aconteça o que acontecer, lá estarei” (França, 2005, p. 45-46).
}

2. Se, por um lado, a narrativa retrata a progressiva dissolução da família Oliveira, por outro, parece integrar a perspetiva do romance histórico, um género romanesco, aliás, que João França também cultivava ${ }^{9}$ : os Oliveiras encontram-se deliberadamente inseridos dentro da realidade concreta de uma época delimitada, entre a Revolta do Leite, de 1936, e o período comummente designado como "Verão Quente", de 1975. O leitor, que conhece a história da (sua) Madeira e de Portugal, vai poder identificar os factos, as questões, as figuras, as instituições, referentes à história real, desde a implantação da República até às repercussões do 25 de Abril, passando pelas políticas do Estado Novo.

Tais coordenadas epocais apresentam-se sob três aspetos: $i$ ) à representação das situações reportadas é dado um cunho de maior autenticidade: a prepotência dos maiorais, a presença do padre nos jantares de convívio que o rico proprietário organizava (denunciando, desse modo, uma Igreja conivente com a burguesia conservadora), o patriarcalismo serôdio, a atração física que descendentes de uma família abastada sentem por serviçais, a corrupção na administração pública, a usurpação da água de rega, as perseguições políticas (a deportação que todos conhecem, mas de que mal se fala), a emigração madeirense para a Venezuela e para a África do Sul, o despertar da consciência política nas classes humildes aquando do 25 de Abril e, finalmente, a promessa de um mundo diferente. ii) As referências emblemáticas desse espaço-tempo são evocadas, mantendo-se alheias à narrativa propriamente dita. São assim mencionados, entre outros: o Cónego Alfredo César Oliveira (fundador do Diário de Notícias da Madeira), o Almirante Reis, João dos Reis Gomes (escritor e jornalista madeirense), Oliveira Salazar, Goulart de Medeiros (governador civil da Madeira), a guerra civil de Espanha, António Menano (fadista), a guerra colonial, Alexander Soljenítsin (o prémio Nobel da literatura de 1970), a canção "Grândola Vila Morena" ou a cedência da independência às colónias portuguesas em África. iii) Estabelecem indícios de posicionamento ideológico, pelo viés de uma possível equivalência histórica. Por exemplo, no seu dizer anacrónico e talvez revelador de superstição, o Comendador, para quem esses vocábulos são

\footnotetext{
Além de contos, crónicas e peças de teatro de caráter histórico, publicou dois romances históricos: A Ilha e o Tempo, em 1972 (2.ed., 2006), e António e Isabel do Arco da Calheta, em 1985. Todavia, em entrevista cedida a José Abel Caldeira, o escritor recusa a designação de "romance histórico" para classificar o seu A Ilha e o Tempo, preferindo a de "romance de ambiente histórico" (V. CALDEIRA, 1989, p. 35). Tal se deve ao facto de o escritor privilegiar a imaginação em vez de seguir e reconstituir episódios atestados e documentados. Na mesma entrevista, João França faz seu o autorretrato enquanto ficcionista: "No fundo, não passo de um ficcionista vocacionado para a liberdade da invenção, ou seja, o prazer de criar personagens e pô-las a viver e resolver os seus problemas. Até mesmo quando trabalho um caso histórico, terá ele de ser uma simples base para o desenvolvimento do enredo, auxiliado pela imaginação" (CALDEIRA, 1989, p. 25).
} 
sinónimos de "revoltosos sanguinários", emprega os termos historicamente firmados de "jacobinos" ou de "mações", quando se refere a "republicanos", e de "bolchevistas", quando se refere a "comunistas" ou "revolucionários de Abril".

Ao certo, o que marcou o tempo de Bonifácio Oliveira, dos filhos e ainda dos netos, foi indiscutivelmente o salazarismo, embora o destino das personagens interesse mais do que a situação política e os acontecimentos históricos em fundo. Eis como João França combina elementos da pequena e da grande História, através de episódios e factos significativos.

Com a mudança de regime operada pela Revolução dos Cravos, abriu-se no território português um período de tensões que conheceu vários picos. O "Verão Quente" de 1975 terá sido um deles. Nesse contexto, o Comendador, um velho de oitenta anos que fora conivente com o regime anterior, refugia-se na sua vivenda de campo no Caniço para fugir aos tumultos no Funchal. As notícias davam conta de manifestações, confrontos, carros armadilhados, atos violentos perpetrados por um grupo independentista, mensagens escritas por esquerdistas nas paredes com palavras de ordem contra as famílias ricas e influentes. Por isso, sempre que olhava em direção ao Funchal, o Comendador simulava uma cuspidela dirigida aos adjuvantes da Revolução. A filha, Lúcia, então uma mulher de sessenta anos, é confrontada por uma servente recém-contratada, Ana de seu nome, que não aceita o reparo, sob a forma de um insulto ofensivo, que a senhora lhe dirige e, num assomo de reivindicação da dignidade individual, responde-lhe na mesma moeda e, de imediato, larga o trabalho para não mais voltar (ibid., p. 18).

Se a velha ordem é assim posta em causa, a nova ordem favorece a inversão de papéis tradicionais. Por exemplo, Marta, a neta de Bonifácio agora com vinte e um anos, não tem pejo em assediar o ingénuo Zé Sabino, o filho da caseira, que, escandalizado, dela foge como do diabo da cruz:

- Desaperta isso.

Entendendo-a, Zé Sabino pestaneja de incredulidade. Começando a recuar, ainda de joelhos, abana a cabeça, a dizer que não, não, senhora.

Então, todo aquele rosto de menina toma a dureza de uma cara adulta, desiludida.

- Ouve, Zé Sabino, ouve - diz ela, por entre dentes poderia fazer de ti, agora, o que muito quisesse, mas já não quero. Detesto gente estúpida. Vai-te! Desaparece da minha vista! Depressa, se não queres que te cape... Com as orelhas em brasa, Zé Sabino foge (ibid., p. 114).

A velha ordem reflete-se na ideologia que Bonifácio representa. Para ele, "a paz do mundo estava no respeito dos inferiores aos superiores" (ibid., p.47), sendo que o sistema de privilégios devia prevalecer sobre qualquer outro sistema. O Comendador também não aceita o pluralismo político a ponto de cortar relações com o seu amigo Alfredo Meireles, pelo facto de este simpatizar com o ideário republicano e, provavelmente, democrata. Em tom de insulto e ironia, desafia-o a deixar o elitista Clube Madeira, cujas cores eram o azul e o branco, e a filiar-se no Marítimo, o clube verde e rubro, associado às classes populares (ibid., p. 34-35).

Mas a verdadeira natureza de Bonifácio revela-se quando o seu compadre, o Engo Januário Gomes, o típico industrial affairiste do regime, lhe propõe montar na sua fazenda uma fábrica de manteiga no lugar da velha azenha desativada. Tratava-se de aproveitar, oportunisticamente, a nova situação que o Decreto-Lei no 26 655, de 4 de junho de 1936, emanado pelo governo central, criava, ao instituir o monopólio do leite através da Junta dos Lacticínios da Madeira. Tal instrumento visava pôr fim à "organização cooperativista" que se estendia "para os lados da Ponta do Sol, já com ramificações nas bandas do norte" (ibid., p. 54). Essa medida teve um forte impacto negativo no até então crescente sector da pecuária e produção de leite, penalizando muitos pequenos e médios camponeses e dando origem, no verão de 1936, a múltiplos levantamentos populares em vários pontos da Ilha (VERÍSSIMO, 1998, p. 100-108; FREITAS, 2011, p. 139-146).

É nesse quadro de fundo que José Talaia, o camponês, ligado a uma cooperativa ${ }^{10} \mathrm{e}$ que não aceitou as contrapartidas que o Comendador lhe "oferecia" em troca da sua "água de giro"11, em período diurno, vem a desaparecer no seguimento de ter sido denunciado à polícia. O filho do camponês promete vingança contra o Comendador. Tendo o jovem Talaia emigrado para a Venezuela, regressa à terra ao fim de trinta e nove anos. Cumprindo a jura, desloca-se à vivenda de Bonifácio Oliveira para enfrentá-lo de novo. Ao divisar um homem velho e gasto, Talaia desiste da ideia de o matar. Todavia, o Comendador, ao dar de caras com ele, sofre um colapso cardíaco fatal, numa cena ilustrativa de uma espécie de trágico moderno.

Se é certo haver dois dramas centrais em Uma família madeirense, a queda de Lúcia que a estigmatizou e o confronto de Bonifácio com os Talaias, o drama

\footnotetext{
${ }^{10}$ A propósito desse dado, vale a pena relacioná-lo com o seguinte apontamento do historiador Nelson Veríssimo: "Todos aqueles que, de imediato, se aplicaram na constituição de cooperativas, viriam a ser perseguidos pela Polícia de Vigilância e Defesa do Estado" (Veríssimo, 1998 , p. 104)

${ }^{11}$ Por giro entende-se o espaço de tempo que medeia duas passagens de água da levada pelo mesmo terreno. São geralmente quinze dias. Se uma propriedade tem direito a quinze horas de água, rega durante quinze horas, de quinze em quinze dias. A rega é sempre feita por sistema de infiltração. Quando se prolongava pela noite fora, decorria à luz duma lanterna de vela.
} 
maior é, em última análise, além dos conflitos internos ou externos, a ação do tempo e o balanço do nível de satisfação da vida que se vive ou viveu. Com efeito, o romance vai sublinhar a solidão de Bonifácio no seu exercício de poder familiar, os sonhos frustrados de Lúcia, os sentimentos de culpa e impotência em Ricardo, os desejos reprimidos de Anselmo, descortinando um horizonte de vidas desperdiçadas e de desprendimento afetivo.

3. A obra de ficção Uma família madeirense assenta na unidade de lugar, já que todo o enredo se desenrola na solarenga vivenda - bem como nas suas imediações de Bonifácio Oliveira, sita na Mãe de Deus, um recanto cimeiro do Caniço, no concelho de Santa Cruz. O romance investe na imagem da casa de campo como metáfora de um espaço insulado, de um refúgio, no sentido literal do termo, representado pelo muro do quintal por trás do qual a personagem principal se sente em segurança contra a realidade incómoda, as contrariedades, as mudanças sociais e políticas. Assim isolado e protegido pelo muro, Bonifácio pode instaurar uma distância com o mundo e manter ainda as ilusões que o tranquilizam. Para o Comendador, é o seu cantinho do céu! As descrições que Bonifácio faz da sua estância "caniceira" - adjetivo pátrio que a voz do texto, fundindo-se com a do patriarca, realça, ao repeti-la várias vezes - são idílicas, dignas de uma coleção de bilhetes-postais. Confrontando com as freguesias de São Gonçalo, Camacha, Gaula, Santo da Serra, e com o mar entre a Ponta do Garajau e os Reis Magos, o Caniço é apresentado por Bonifácio como o bendito lugar das origens do ramo varonil da família Oliveira, a terra "sagrada" que viu nascer o seu progenitor, Arlindo Venâncio Gaspar Vaz de Oliveira.

Essa estratégia permite ao autor construir um espaço simbólico, entendido como metonímia da família tradicional, visto as personagens assim reunidas num só lugar estarem condenadas a aceitarem-se e a conviverem umas com as outras, mesmo quando não partilham das mesmas visões do mundo. A última geração tende a não suportar aquele lugar que tanto encanta o avô. Após um almoço em família e quando era suposto todos dormirem a sesta, os "meninos" - termo usado pela servente para designar os netos do Comendador - procuram sair dali para espairecer. Marta não consegue escapulir-se. Benjamim e Clara vão apanhar ar para a esplanada de um café-restaurante na Camacha; Venceslau vai ter com eles. Podem enfim falar à vontade sobre o 25 de Abril e debater a "natureza humana". Esta cena apresenta-se, significativamente, como a única que se desenrola fora da propriedade do Comendador.

Além do mais, toda a encenação desse microcosmo vai facilitar a desconstrução de uma família abonada e conservadora, porque demasiado idealizada pelo patriarca. No final de contas, estamos perante uma forma romanesca representativa da "imobilidade movediça", uma das imagens que Yannick Preumont adota para definir o período de transição entre dois mundos que toda a saga familiar tende a refletir (PREUMONT, 2004, p. 11), ilustrativa da inevitabilidade do declínio. Independentemente de o Caniço poder ser a terra ancestral de que determinada família se orgulha, o certo é que, com a sua levada, vales, ribeiras, costa litorânea, vegetação selvagem e cultivada, gruta escondida e casario, o Caniço permanecerá, como qualquer outro lugar, o território metafísico e indiferente aos homens que sempre foi.

Tudo somado, a narrativa de João França alberga pelo menos três formulações minimalistas do género romanesco, representadas pela saga familiar, pela crónica de costumes e pelo romance histórico.

Asilando uma crítica à sociedade madeirense das épocas retratadas, o livro tem o mérito de desmontar, de modo implacável, alguns "mitos" convencionados, designadamente a idealização de uma genealogia duvidosa, o culto das aparências, a virtuosa mulher madeirense, a ordem que o Estado Novo preconizava, a bondade da argumentação de homens de negócios ou o senso crítico de certo padre católico, a subserviência do bom povo ou a desordem que o 25 de Abril instalou.

Desconstruindo a hipocrisia bem-pensante das classes favorecidas, João França, qual humanista, faz-se cúmplice da causa das figuras subalternas vistas como identidades sociais. Em Uma família madeirense, o patriarcalismo está no seu auge mas o leitor perceciona o princípio do fim de uma era, porque homens e mulheres tomam consciência do papel que a sociedade lhes impõe e se preparam para participar na mudança. O escritor denuncia sobretudo a prepotente ordem do patriarcalismo anacrónico, encenando, de modo eficaz, o destronamento do patriarca. Com a morte do Comendador, o romance revela, de forma exemplar, que a defesa da moral ultraconservadora só interessa aqueles que condenam os outros - mesmos os mais próximos - à dependência, à submissão e à reclusão.

$\mathrm{O}$ romance, que consubstancia a crónica familiar dos Oliveiras, deve compreender-se como uma forma de superar o passado por parte da geração de Abril de 1974. Para formar e informar os jovens leitores, o conhecimento do passado insular é ainda um dos grandes temas e desafios literários aos quais os escritores da atualidade não devem renunciar. João França, com este romance sobre as mudanças de mentalidade, proporciona ao leitor uma visão lúcida, penetrante e crítica da Madeira do 
séc. XX e dos espaços da identidade cultural portuguesa. É razão mais do que suficiente para voltar a dar-lhe mais atenção, para falar de novo de um escritor madeirense cujas obras esquecidas deviam ser redescobertas.

\section{Referências}

ANDRADE, Irene Lucília. Preâmbulo. In: FRANÇA, João. Uma família madeirense. Madeira: Câmara Municipal de Santa Cruz, 2005. p. 7-8.

CALDEIRA, José Abel de O. M. Ínclitos ilhéus. Funchal: Edição do autor, 1989.

FRANÇA, João. Uma família madeirense. Madeira: Câmara Municipal de Santa Cruz, 2005.

FREITAS, João Abel de, A Revolta do Leite - Madeira 1936. Lisboa: Edições Colibri.

PREUMONT, Yannick. La fin des bourgeois de Camille Lemonnier face aux grandes chroniques familiales européennes. Textyles [en ligne]. v. 24, p. 98-107, 2004. Mis en ligne le 12 juin $2012<$ http://textyles.revues.org/766>. Consulté le 11 octobre 2015.
ROCHA, Clara. Representações da autoridade antes e depois do 25 de Abril: pequena antologia de retratos de Salazar. In: SIMÕES, Manuel G.; CASTRO, Ivo; CORREIA, João David Pinto (Org.), Memória dos afectos: homenagem da Cultura Portuguesa a Giuseppe Tavani. Lisboa: Edições Colibri, 2001. p. 23-37.

SCHEIDL, Ludwig. Crónica de família ou romance histórico: o romance de Arno Geiger Es geht uns gut e os traços de Joseph Roth. In: MINGOCHO, Maria Teresa Delgado; GIL, Maria de Fátima; CASTENDO, Maria Esmeralda (Coord.). Miscelânea de estudos em homenagem a Maria Manuela Gouveia Delille. Vol. I. Coimbra: Faculdade de Letras da Universidade de Coimbra/Centro de Investigação em Estudos Germanísticos/ Minerva, 2011. p. 369-374.

TADIÉ, Jean-Yves. Le roman au XXe siècle. Paris: Belfond, 1990.

VERÍSSIMO, Nelson. A revolta do leite. In: Passos na calçada: crónicas. Funchal: Editorial Calcamar, 1998. p. 100-108. (Série Novecentos 1).

Recebido: 12 de novembro de 2016 Aprovado: 18 de novembro de 2016 Contato: thierry@uma.pt 